\title{
Editorial
}

\section{Low-Power Wearable Healthcare Sensors}

\author{
Robert Simon Sherratt ${ }^{1, *(1)}$ and Nilanjan Dey ${ }^{2}$ (i) \\ 1 Department of Biomedical Engineering, University of Reading, Reading RG6 6AY, UK \\ 2 Techno India College of Technology, Kolkata, West Bengal 700156, India; neelanjan.dey@gmail.com \\ * Correspondence: r.s.sherratt@reading.ac.uk
}

Received: 21 May 2020; Accepted: 25 May 2020; Published: 27 May 2020

check for updates

\section{Introduction}

Medical science has taken great steps to enable us to live longer and healthier lives. While hospitals are vital for intervention-based healthcare, hospital care is expensive, increasing in cost, and with the continual increase in the global elderly population, we need solutions to enable people to stay healthy. While smart home technology solutions are enabling people to live in their homes for longer, research has shown that more personalized data are needed to improve services and decisions, and this is where wearable devices are proving their worth. Sensors can be placed on and around the body, in clothing, in shoes, in jewelry, and in many other accessories to measure movement, physiology, environment, and even mood/emotion. Such technology will become more common, and indeed vital, in long-term health monitoring. Perhaps the real potential of such devices is not just to monitor, but to have interactive communication with cloud services to offer personalized and ongoing real-time healthcare advice, enabling people to manage their health and to reduce hospital admissions. Therefore, the challenge of the next generation of wearable healthcare devices is to offer a wide range of sensing, computing, communication, and human-computer interactions, all within a tiny device with limited resources and electrical power.

\section{Low-Power Wearable Healthcare Sensors}

The aim of this Special Issue was to highlight the research challenges being tackled to enable the next generation of low-power wearable healthcare sensors. Six interesting and thought-provoking papers have been selected which present a wide range of challenges and solutions:

1. Enhancements to software to manage and constrain peak electrical current consumption in a wearable healthcare device [1],

2. A wearable low-power insulin delivery method for people with diabetes [2],

3. The design of an Internet of Things (IoT)-based sensor node for eHealth [3],

4. Human joint angle estimation and movement analysis using polymer optical fiber curvature sensors and inertial measurement units [4],

5. A neural spike detector system as an interesting roadmap to wearable devices monitoring brain activity [5],

6. CMOS Interfaces for the detection of biological fluids (sweat, tears, saliva, and urine) as part of a connected internet-of-wearables [6].

We hope you enjoy reading this Special Issue and are inspired to address the technological challenges to help prolong human lives.

\section{Conclusions}

Wearable devices have become a must-have consumer device. Such devices are commonly seen in healthcare, fitness, and location-tracking applications, but this is just the start. The technology 
behind wearable devices is now maturing to the point where consumer-grade devices can be used to help people manage chronic conditions, including Parkinson's disease, stroke, diabetes, and dementia. However, for reliable deployment at home, wearable devices must now balance the need to operate for a long time between charges with having ever increasing computational and communicative resources.

Research to enable wearable devices to last longer per charge is extremely important because, as these devices are almost exclusively powered by batteries, their size is limited for user comfort and usability. Devices that last a long time per charge enable the long-term monitoring of the user for improved health decisions. While battery capacity can be improved, research also indicates that smarter and lower-power CPU architectures, improved wireless connectivity, and task scheduling can also enable devices to last longer. In the future, wearable devices will not only monitor movement and heartrate, but also incorporate sensors to capture the users' biological states, as we are already now seeing for emotion and stress [7].

Author Contributions: Conceptualization, R.S.S. and N.D.; methodology, R.S.S. and N.D.; writing-review and editing and project administration, R.S.S. and N.D. All authors have read and agreed to the published version of the manuscript.

Funding: This research received no external funding.

Conflicts of Interest: The authors declare no conflict of interest.

\section{References}

1. Sherratt, R.S.; Janko, B.; Hui, T.; Harwin, W.S.; Dey, N.; Díaz-Sánchez, D.; Wang, J.; Shi, F. Task Scheduling to Constrain Peak Current Consumption in Wearable Healthcare Sensors. Electronics 2019, 8, 789. [CrossRef]

2. Berián, J.; Bravo, I.; Gardel, A.; Lázaro, J.L.; Hernández, S. A Wearable Closed-Loop Insulin Delivery System Based on Low-Power SoCs. Electronics 2019, 8, 612. [CrossRef]

3. Petrellis, N.; Birbas, M.; Gioulekas, F. On the Design of Low-Cost IoT Sensor Node for e-Health Environments. Electronics 2019, 8, 178. [CrossRef]

4. Valencia-Jimenez, N.; Leal-Junior, A.; Avellar, L.; Vargas-Valencia, L.; Caicedo-Rodríguez, P.; Ramírez-Duque, A.A.; Lyra, M.; Marques, C.; Bastos, T.; Frizera, A. A Comparative Study of Markerless Systems Based on Color-Depth Cameras, Polymer Optical Fiber Curvature Sensors, and Inertial Measurement Units: Towards Increasing the Accuracy in Joint Angle Estimation. Electronics 2019, 8, 173. [CrossRef]

5. Vallicelli, E.A.; Reato, M.; Maschietto, M.; Vassanelli, S.; Guarrera, D.; Rocchi, F.; Collazuol, G.; Zeitler, R.; Baschirotto, A.; De Matteis, M. Neural Spike Digital Detector on FPGA. Electronics 2018, 7, 392. [CrossRef]

6. Dei, M.; Aymerich, J.; Piotto, M.; Bruschi, P.; del Campo, F.J.; Serra-Graells, F. CMOS Interfaces for Internet-of-Wearables Electrochemical Sensors: Trends and Challenges. Electronics 2019, 8, 150. [CrossRef]

7. Zamkah, A.; Hui, T.; Andrews, S.; Dey, N.; Shi, F.; Sherratt, R.S. Identification of suitable biomarkers for stress and emotion detection for future personal affective wearable sensors. Biosensors 2020, 10, 40. [CrossRef] [PubMed]

(C) 2020 by the authors. Licensee MDPI, Basel, Switzerland. This article is an open access article distributed under the terms and conditions of the Creative Commons Attribution (CC BY) license (http://creativecommons.org/licenses/by/4.0/). 